\title{
DESIGN AND STRUCTURAL ANALYSIS OF A POWERED WHEELCHAIR TRANSMISSION
}

\author{
GEONEA Ionut Daniel \\ Ph.D. Eng/ Assistant professor, Faculty of Mechanics / Department of Applied Mechanics, University of Craiova, \\ Craiova, Romania, igeonea@yahoo.com
}

DUMITRU Nicolae

Ph.D. Eng/Professor, Faculty of Mechanics / Department of Applied Mechanics, University of Craiova, Craiova, Romania, nicolae_dtru@yahoo.com

MARGINE Alexandru

Ph.D. Eng/Professor, Faculty of Mechanics / Department of Applied Mechanics, University of Craiova, Craiova, Romania, fam_margine@yahoo.com

\begin{abstract}
In this paper are presented the author's researches on designing, dynamical and structural evaluation of a transmission for a wheelchair, intended to persons with locomotors disabilities. The kinematics of proposed transmission is analyzed in order to realize a proper synthesis and design of gears. A 3D model of the transmission and wheelchair are designed in Solid Works, and they will be used for the dynamic simulation of the wheelchair robotic system in Adams software. In Adams is analyzed wheelchair trajectory and dynamics for a combined trajectory: linear motion and steering. Dynamic parameters obtained from simulation are used to perform a finite element analysis of bevel and worm gears. Simulation results reveal the transmission dynamics parameters, emphasize the efficiency of the transmission and enable implementation of this design to a wheelchair model.
\end{abstract}

Key words: Wheelchair, design, dynamics, differential transmission.

\section{Introduction}

There are many examples of assistive devices for people with manipulative and locomotive disabilities: wheelchairs, locomotion assistive devices, exoskeletons. These devices enable disabled people to perform many activities of daily living thus improving their quality of life. Disabled people are increasingly able to lead an independent life and play a more productive role in society [1, 3, 5].

Wheelchair is still the best transportation means for disabled people, since its invention in 1595 (called an invalids chair) for Phillip II of Spain by an unknown inventor. They have since evolved into complex multi-degree-of-freedom mechanical and electro-mechanical devices and robotic systems [2, 4, 5, 6, 7, 8, 9]. Despite rapid scientific and technological progress, there has been very little innovation in wheelchair design over the last 200-300 years. The folding wheelchair came in 1933, and powered wheelchairs were developed in the early 1970 [3].

Power wheelchairs are used predominantly by people with both lower and upper extremity impairment resulting from cerebral palsy, high-level spinal cord injury, or muscular dystrophy. The propulsion system of powered wheelchairs typically consists of a pair of motors, one for each drive wheel, and a drive train consisting of gears, belts and other mechanical elements that couples the motor's shaft to the drive wheel shaft. Speed and torque generated by each motor is controlled by modulating the pulse width. Solid state relays are generally used to switch supply voltage polarity to change the running direction of PM (permanent magnet) motors [3, 5].

On a smooth level surface, relatively little torque is required to propel the wheelchair and occupant at constants speeds of up to $5 \mathrm{~m} / \mathrm{s}$. If this were the only requirement, small motors of a few hundred watts capacity would serve. But wheelchairs must overcome obstacles, usually at low speed, climb substantial grades and accelerate at reasonable rate. These conditions demand high torque, most 
often at low speed. Thus, most powered wheelchairs are equipped with motors, electronic controls that are much larger than necessary for constant level propulsion and with poor efficiency most of the time since high torque is obtained only at low speed [9].

The wheelchair's control module converts positional information from the joystick into power signals to the motors. Control modules are microprocessor based, have many adjustable parameters and utilize feedback to sense whether the motor is responding properly to the joystick position $[3,5]$.

This research brings arguments for a mechanical transmission that achieves the differential movement, on which the traction and the steering components are controlled by separately motors with suitable synthesis to achieve the proper angular speed difference of wheels [16]. The model will be equipped with motion controller, using a pulse width modulated DC to DC converter (PWM).

\section{Kinematical study of wheelchair transmission}

Kinematic scheme of wheelchair transmission is shown in Figure 1. Shaft I is actuated by straight line displacement electric motor $\mathrm{M}_{1}$, and steering is performed by steering motor $\mathrm{M}_{2}$ placed on shaft V.

Bevel gears, $(10,12)$ and $\left(10^{\prime}, 12\right.$ ') are planetary gears and they are mounted on shafts (IV, III), respectively (IV', III'), with pins assembly. Bevel gears, $(11,13)$, and $\left(11^{\prime}, 13^{\prime}\right)$ are satellites gears. Satellites gears are mounted on needle bearings to axes fixed on differential casing, and achieve a planetary motion. To calculate the transmission ratio, the principle of motion reversing is applied (called Willis principle). To straight line displacement the traction wheels of the wheelchair spin at the same angular velocity. The motion is transmitted from worm gears 6-5 to the shaft II and by means of final transmission, with cylindrical gears 2-4, to wheelchair wheels, Rs (left wheel) and Rd (right wheel).

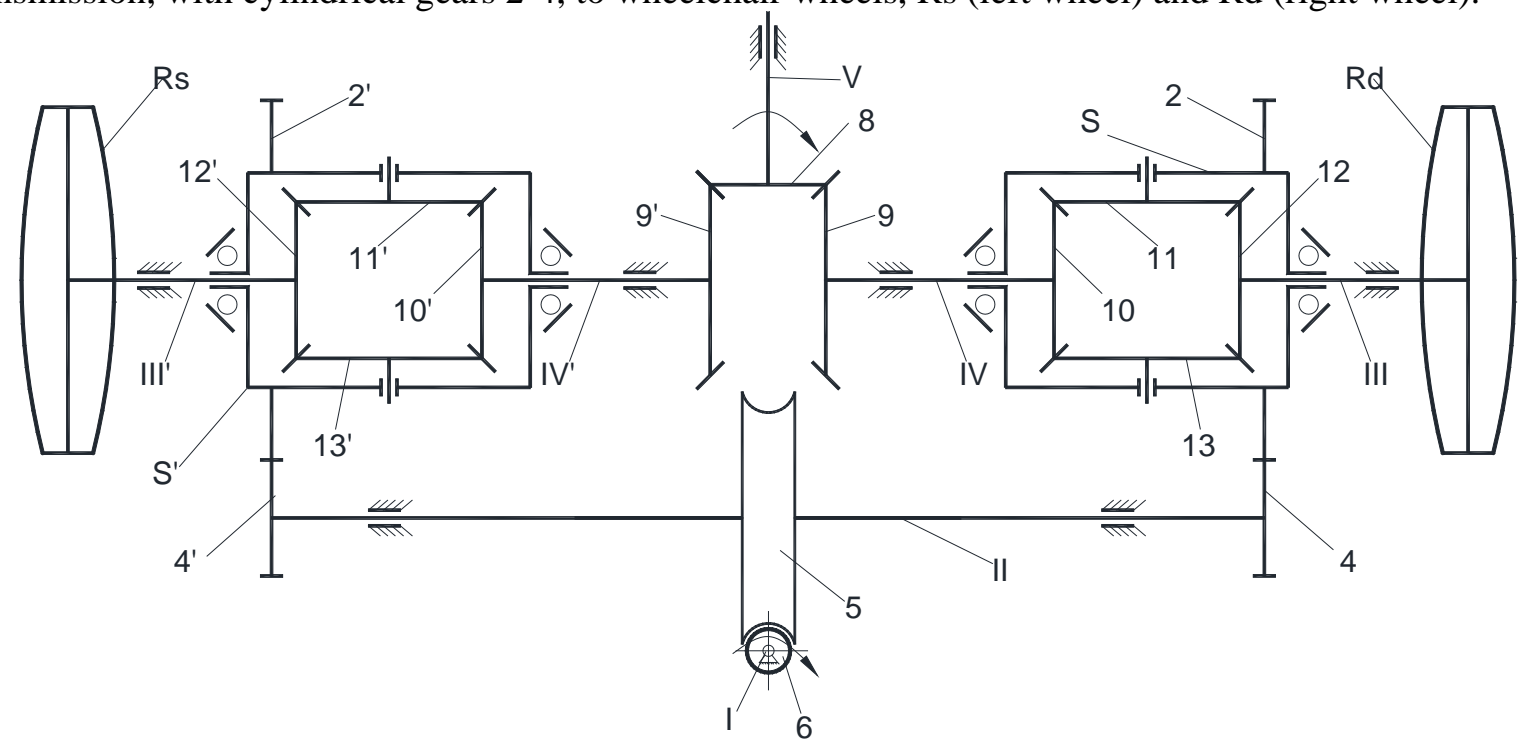

Figure 1: Kinematical scheme of wheelchair transmission.

For steering, the motion is transmitted from motor $M_{2}$ to shaft $V$, trough bevel gears $(8,9),(10$, 11), $(11,12)$ to semi-axis III, respectively to motor wheel Rd. For left wheel Rs the transmission flow go through bevel gears $\left(8,9^{\prime}\right),\left(10^{\prime}, 11^{\prime}\right),\left(11^{\prime}, 12^{\prime}\right)$ to semi-axis III'. Those two wheels Rd and Rs will spin with the same angular speed and opposite rotation sense. Casing S, S' and spur gear (2, 2') in not moving (the motor $\mathrm{M}_{1}$ is turned off).

The motion transmission chain for straight line displacement and the motion transmission chain for steering, of the wheelchair, are expressed by relation (1).

$$
\begin{aligned}
& M_{1}-I-i_{65}^{w}-I I-i_{42}^{c}-I I I-R d \quad M_{2}-V-i_{89}^{k}-I V-i_{1011}^{k}-i_{11}^{k}-I I I-R d \\
& M_{1}-I-i_{65}^{w}-I I-i_{4^{\prime} 2^{\prime}}^{c}-I I I-R s^{\prime} \quad M_{2}-V-i_{89^{\prime}}^{k}-I V^{\prime}-i_{10^{\prime} 11^{\prime}}^{k}-i_{11^{\prime} 12^{\prime}}^{k}-I I I I^{\prime}-R s
\end{aligned}
$$

Where: $\mathrm{M}_{1}$ - traction motor; $i_{65}^{w}$-worm gear ratio; $i_{42}^{c}$-final transmission ratio; Rd and Rs, right and left wheel, I, II and III - shafts; $\mathrm{M}_{2}$ - steering motor; $i_{89}^{k} i_{89^{\prime}}^{k} \quad$-bevel gear ratio; $i_{1011}^{k}$-bevel gears 10, 11 ratio; $i_{112}^{k}$-bevel gears 11, 12 ratio; Rd and Rs, right and left wheel, III, IV and V - shafts.

For wheelchair straight line displacement when both drive wheels encounter the same resistance to ground, is valid relation (1). For steering, the governing equations of the wheels angular velocity, are:

$$
\omega_{s}=\frac{\omega_{10}+\omega_{12}}{2}
$$


From Eq. 2, the angular velocity of the central gear (planetary) is twice the angular velocity of the differential casing. If the steering motor is turned off, then $\omega_{10}=0$, from Eq. (2) it is obtained:

$\omega_{12}=2 \omega_{s}=2 \omega_{2}$

In the same way: $\omega_{10}^{\prime}=0$, it is obtained: $\omega_{12^{\prime}}=2 \omega_{S^{\prime}}=2 \omega_{2^{\prime}}$

Taking into account the gears ratio, is obtained the equation (4):

$\omega_{s}=\frac{\omega_{M_{1}}}{i_{65}^{w} \cdot i_{42}^{c}}[\mathrm{rad} / \mathrm{s}]$, is the motion received from the traction motor.

Where:

$\omega_{M_{1}}$-is traction motor angular velocity; $i_{65}^{w}$-worm gear ratio; $i_{42}^{c}$-spur gears $4-2$ transmission ratio.

In case of curve displacement of the wheelchair, is obtained the equation (5):

$\omega_{10}=\frac{n_{M_{2}}}{i_{89}^{k}} ; \omega_{10}{ }^{\prime}=\frac{n_{M_{2}}}{i_{89^{\prime}}^{k}}-$ is the motion received from steering motor $\mathbf{M}_{2}$.

Notations used are:

$\omega_{10}, \omega_{12}$-absolute angular velocity of bevel planetary gears 10 and 12 , considered in relation to differential casing;

$\omega_{10}^{S}=\omega_{10}-\omega_{S}$-relative angular velocity of gear 10, towards differential casing $\mathrm{S}$;

$\omega_{12}^{S}=\omega_{12}-\omega_{S}$-relative angular velocity of gear 12 , towards differential casing S;

$\omega_{11}, \omega_{13}$ - is relative angular velocity of satellite gears 11 and 13, towards differential casing S;

$\omega_{S}$ - is absolute angular velocity of differential casing upon wheelchair frame;

Relations deducted above are helpful to the kinematic synthesis of wheelchair transmission. These relations are used to establish gears ratio, upon is designed in Solid Works, transmission 3D model.

\section{Design and motion simulation of the wheelchair}

Based on the kinematic scheme of the transmission (Figure 1) it is performed the design calculations of gears. Input data, respectively powers and angular speeds on shafts are known, basic kinematic and dynamics parameters being establish. We calculate geometric elements of gears, upon we design the 3D models of gears, with GearTrax and Solid Works software. Also it is performed transmission shafts and bearings calculation. Gears ratios and dimensions are given in Table 1.

Table 1: Gears ratios and dimensions

\begin{tabular}{|c|c|c|c|c|c|}
\hline Gear pair & $\begin{array}{c}\mathrm{Z}_{2}=34 \\
\mathrm{Z}_{4}=18\end{array}$ & $\begin{array}{c}\mathrm{Z}_{8}=13 \\
\mathrm{Z}_{9}=33\end{array}$ & $\begin{array}{c}\mathrm{Z}_{6}=1 \\
\mathrm{Z}_{5}=17\end{array}$ & $\begin{array}{c}\mathrm{Z}_{10}=16 \\
\mathrm{Z}_{11}=10\end{array}$ & $\begin{array}{c}\mathrm{Z}_{12}=16 \\
\mathrm{Z}_{13}=10\end{array}$ \\
\hline Gears ratio[-] & 1,88 & 2,538 & 17 & 1,6 & 1,6 \\
\hline Gears module [mm] & 3 & 3 & 3,5 & 2,5 & 2,5 \\
\hline $\begin{array}{c}\text { Gears rolling diameter } \\
\text { [mm] }\end{array}$ & $\begin{array}{c}\mathrm{dw}_{2}=54,84 \\
\mathrm{dw}_{4}=101,5\end{array}$ & $\begin{array}{c}\mathrm{dw}_{8}=39,0 \\
\mathrm{dw}_{9}=99,8\end{array}$ & $\begin{array}{c}\mathrm{dw}_{6}=26,25 \\
\mathrm{dw}_{5}=58,8\end{array}$ & $\begin{array}{c}\mathrm{dw}_{10}=40 \\
\mathrm{dw}_{11}=25\end{array}$ & $\begin{array}{c}\mathrm{dw}_{12}=40 \\
\mathrm{dw}_{13}=25\end{array}$ \\
\hline
\end{tabular}

Calculated data allowed us to design the 3D model of designed wheelchair transmission, which is presented in Figure 2. Differential transmissions have been mounted on the wheelchair structure and the assembly view is presented in Figure 3 . The weight of the entire assembly (Figure 3 ) is $\approx 45 \mathrm{~kg}$. 


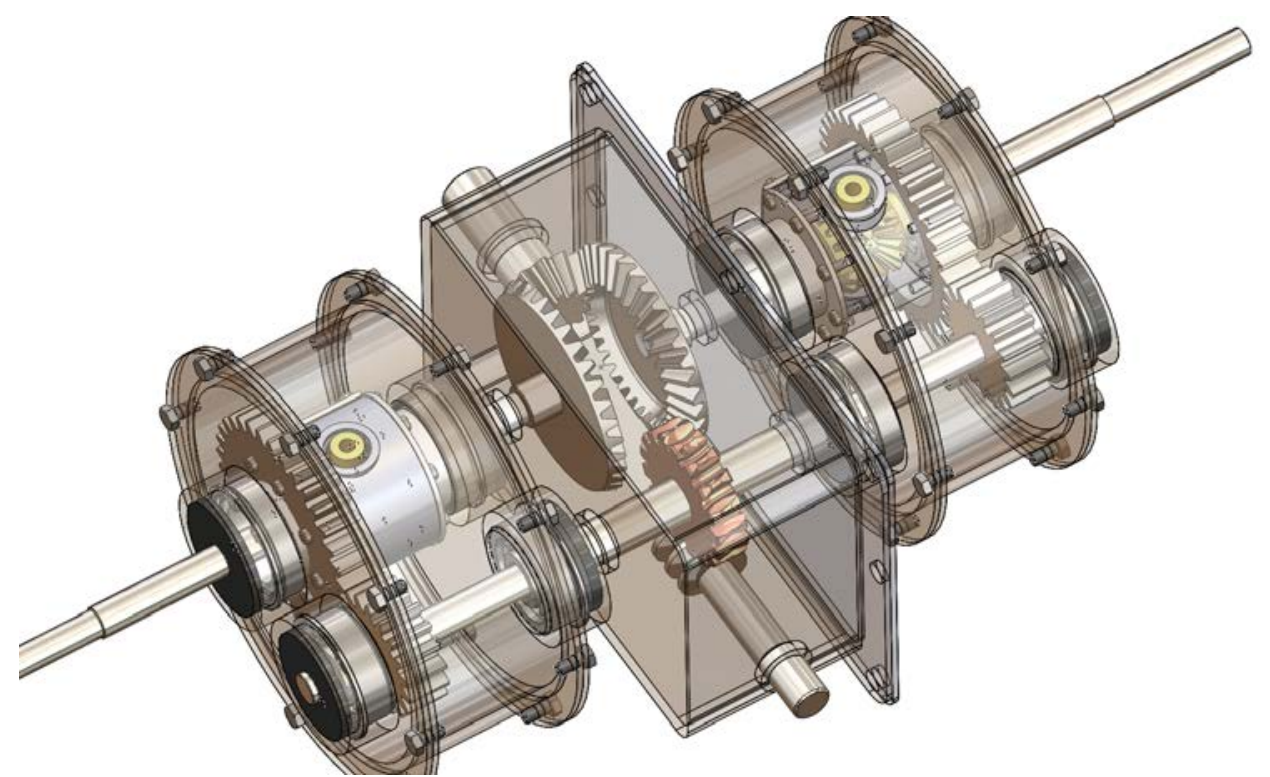

Figure 2: Wheelchair transmission assembly in Solid Works.
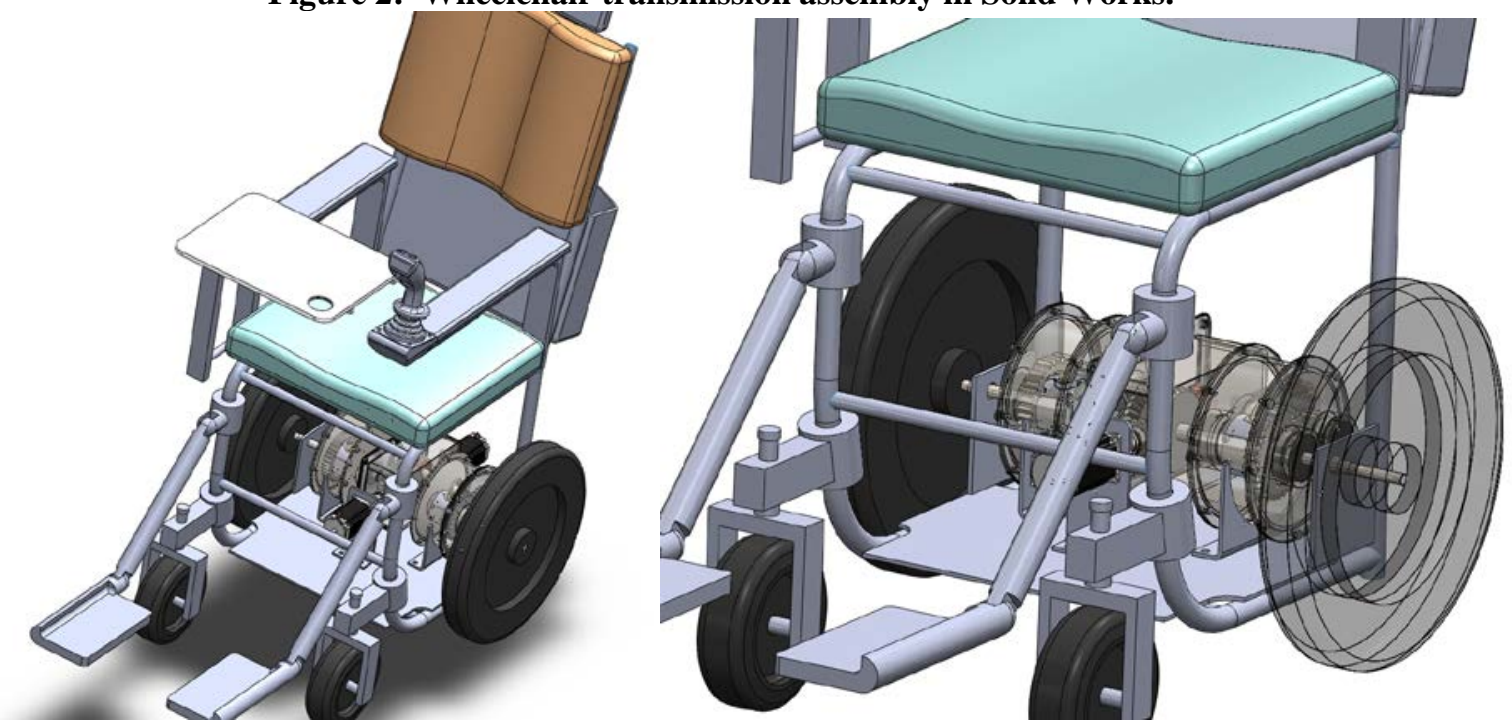

Figure 3: Wheelchair assembly in Solid Works.

It is achieved robotic wheelchair workspace analysis in Adams, in one assumption: a combined trajectory composed of a straight line motion with steering. For this case of simulation are active both motions, straight line and steering. Functions used in Adams to define straight line motion and steering motion are given by Eq. 6. Traction motor spins with $38 \mathrm{rad} / \mathrm{s}$, and steering motor with $3.5 \mathrm{rad} / \mathrm{s}$.

IF (time-2: 38, 0, IF (time-4: 0, 38, 38)) - for traction motion (shaft I)

IF (time-2: 0, 0, 3.5) - for steering motion (applied to shaft $V$ )
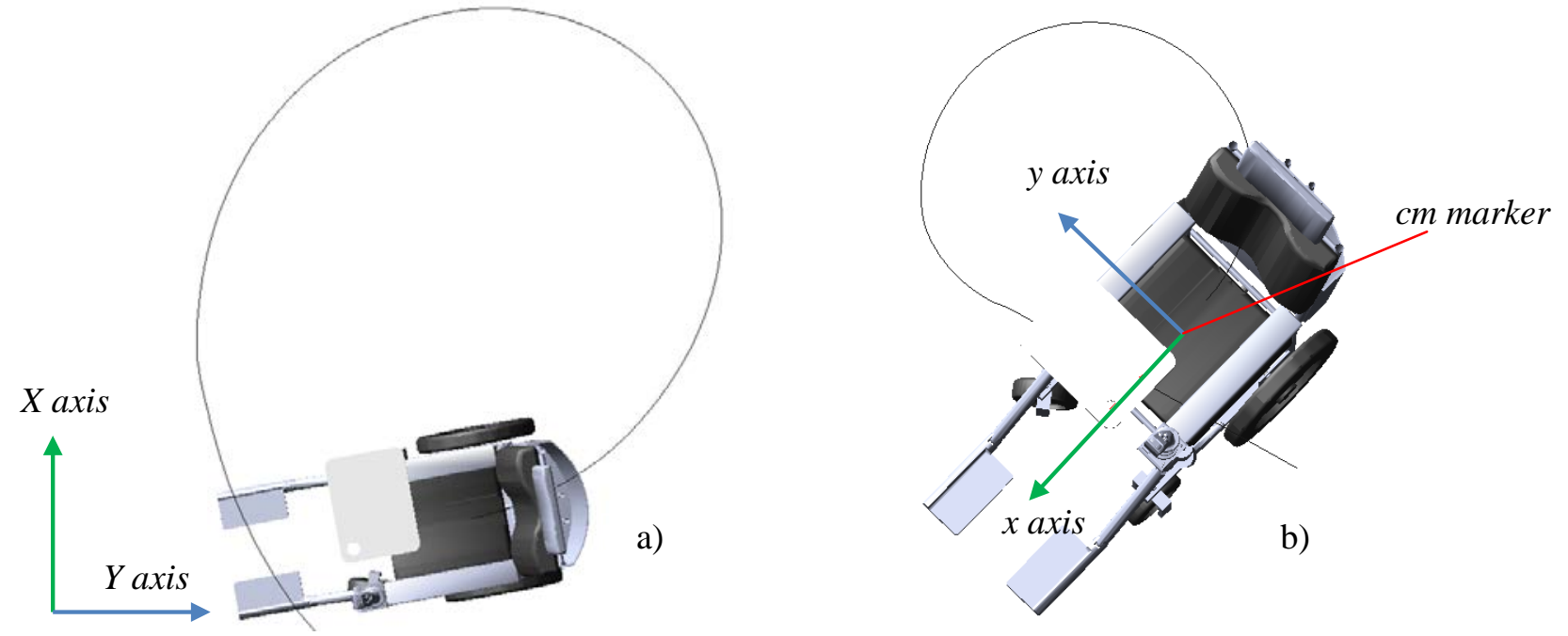
Figure 4: Wheelchair trajectory: combined motion (a) and steering motion (b).

In case of combined motion simulation, the wheelchair obtained trajectory is presented in Figure 4, a. The obtained torque variation, for the traction motor is presented in Figure 5, a, and for steering motor the torque variation is shown in Figure 5, b.
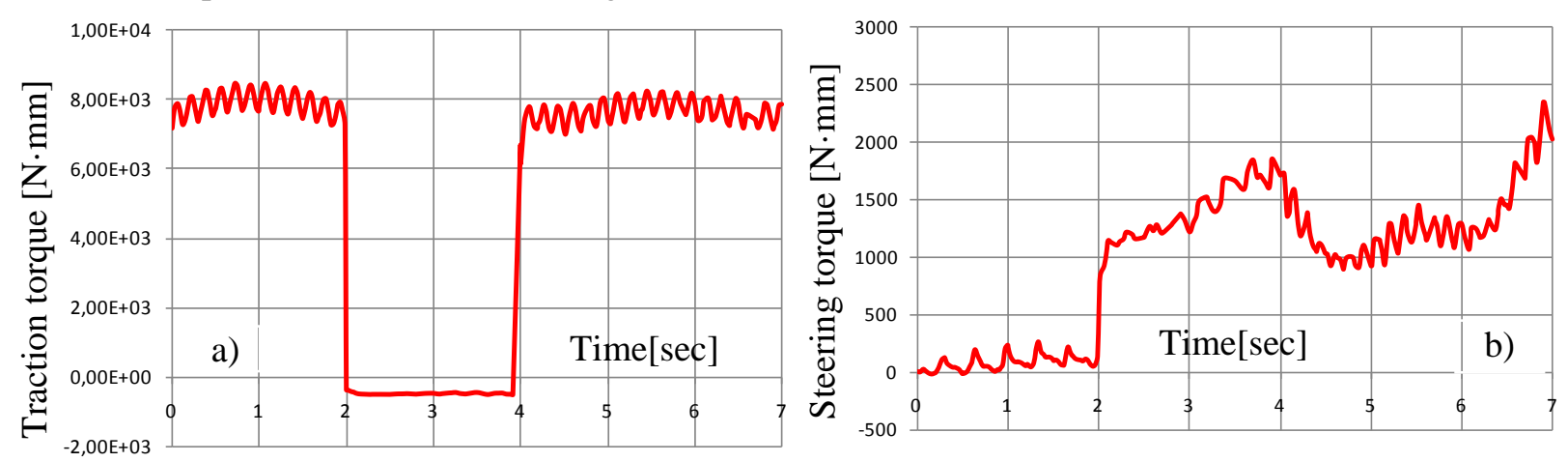

Figure 5: Traction and steering torque variation, in case of combined motion.

Maximum values of traction and steering torque will be used for finite element analysis of worm and bevel gears in Ansys.

\section{Transient structural analysis of worm and bevel gears in Ansys}

To study the contact problem for bevel and worm gears it is performed a transient structural analysis in Ansys software. The purpose of finite elements analysis of worm and bevel gears is to establish the values of stress, strain and elastic deformations which occur. For that purpose the 3D model of gears is transferred into Ansys database, are specified the material properties, the model joints, and contact parameters. The loads are specified accordingly to torque moments calculated from the Adams dynamic model. For bevel pinion is specified the maximum value of steering torque, by $2.5 \mathrm{Nm}$, as in Figure 5, b and for worm pinion is specified as load the traction torque value, by $8 \mathrm{Nm}$. Mesh models of worm and bevel gears are presented in Figure 6.

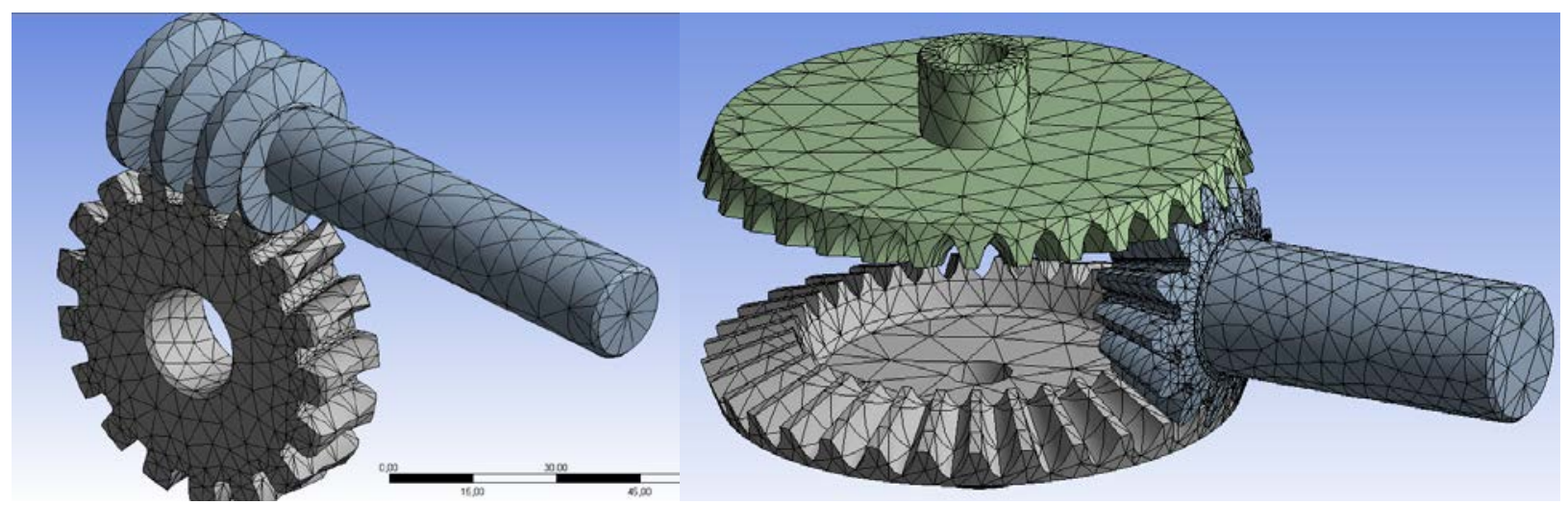

Figure 6: Finite elements model of worm and bevel gears.

Solving in Ansys the models and processing the results, it is obtained the equivalent von Misses stress distribution, for worm gear and for bevel gear models. Obtained results for stress distribution of worm gear are presented in Figure 7. The maximum value of equivalent (von-Mises) stress is 35,5 MPa. 


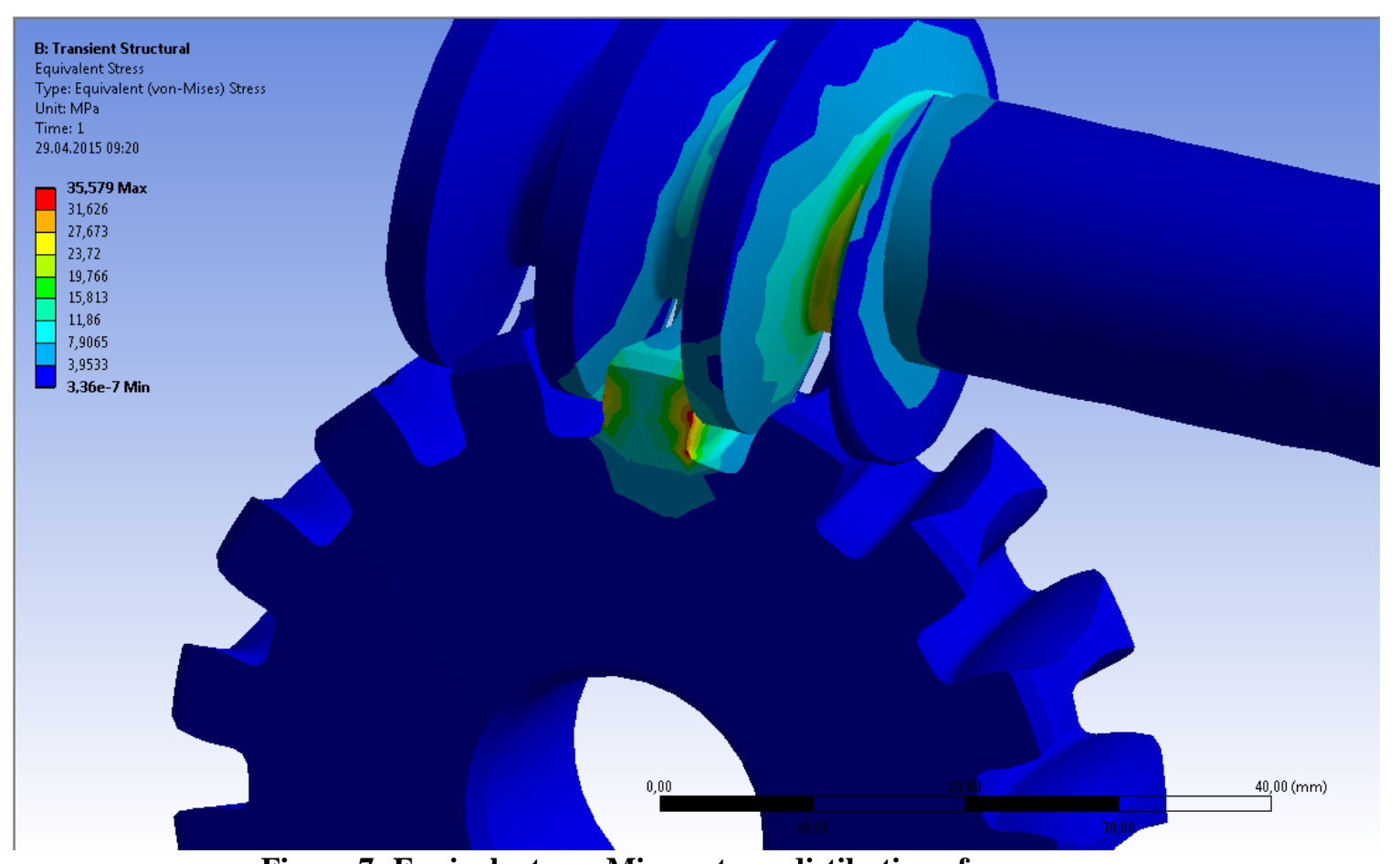

Figure 7: Equivalent von Misses stress distibution of worm gear.

In case of bevel gears, used for steering motion, the distribution of equivalent stress is presented in Figure 8. For this model, the maximum value of equivalent (von-Mises) stress is $14,2 \mathrm{MPa}$. As a conclusion, for straight line displacement and steering of the wheelchair the level of transmission gears load is relatively low. Values for traction and steering torques would be higher in case of a road with climb. Also, in case of displacement of an uneven terrain this value would increase.

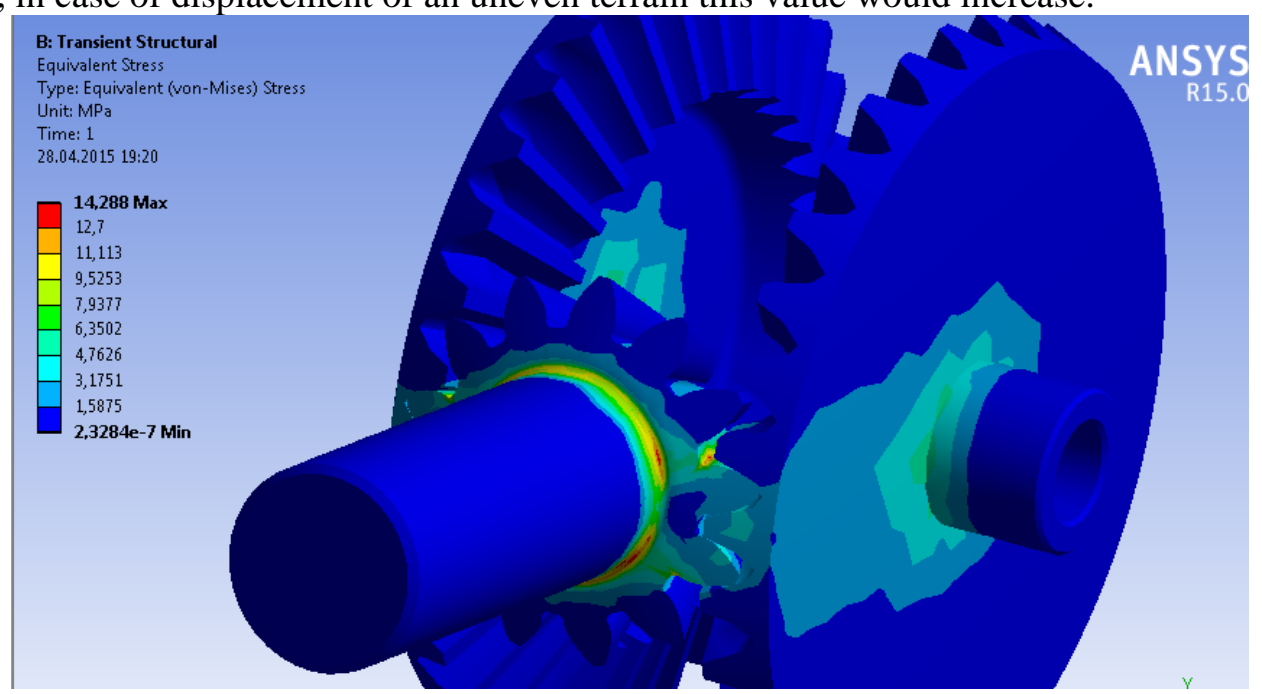

Figure 8: Equivalent von Misses stress distibution of bevel gear.

\section{Conclusions}

This paper proposes to develop a kinematic and dynamic analysis model of a robotic wheelchair. The virtual model of the wheelchair is designed in Solid Works. Proposed solution uses two kinematic chains, one for straight line motion and second for steering motion. The solution uses two motors: straight line motion motor and steering motor. The motors can operate independently or in correlation, in this case the wheelchair can be drive with different steering radius. Dynamic simulation reveals motion trajectories of wheelchair, kinematic and dynamic parameters of the system: running speed, propulsion and steering torque. From Adams simulation is determined that the propulsion motor necessary torque, when the wheelchair carries a $70 \mathrm{~kg}$ human, is $8 \mathrm{Nm}$ and the steering torque is by $2.5 \mathrm{Nm}$. Structural analysis performed in Ansys reveals the equivalent stress distribution, for the transmission gears. 
Acknowledgments: This work was supported by the strategic grant POSDRU/159/1.5/S/133255, Project ID 133255 (2014), co-financed by the European Social Fund within the Sectorial Operational Program Human Resources Development 2007-2013.

\section{References}

1. Geonea I., Dumitru N., Design and motion analysis of a powered Wheelchair, Applied Mechanics and Materials, Vol. 772 (2015), pp. 613-620, doi:10.4028/www.scientific.net/AMM.772.613.

2. Geonea I., Dumitru N., Motion analysis of a robotic wheelchair, Proceedings of 24 International Conference Robotics in Alpe Adria Danube -RAAD 2015, 27-29 May, Bucharest, Romania (to be published).

3. Kumar Vijay, Assistive Devices for People with Motor Disabilities, Wiley Encyclopedia of Electrical and Electronics Engineering Assistive Devices for People with Motor Disabilities, 1997.

4. Kong D., Nonlinear Contact Analysis of Gear Teeth for Malfunction Diagnostics, Conference and Exposition on Structural Dynamics, 2008.

5. Modak G. S., Review Article: Evolution of a Stair-Climbing Power Wheelchair, IOSR Journal of Mechanical and Civil Engineering (IOSR-JMCE), pp. 36-41, 2009.

6. Pires G., Autonomous Wheelchair for Disabled People, Proc. IEEE Int. Symposium on Industrial Electronics (ISIE97), Guimarães, 797-801, 1997.

7. Rajasekar R., Design and fabrication of staircase climbing wheelchair, Int. J. Mech. Eng. \& Rob. Res., 2013.

8. Razak S., Design And Implementation Electrical Wheel Chair For Disable Able To Stairs Climbing By Using Hydraulic Jack, IOSR Journal, Volume 7, Issue 3 (2013), pp.82-92.

9. Reswick JB., Automatic transmission for electric wheelchairs, J. Rehabil. Res. Dev., 1985.

10. Salmin H., Design and Implementation of an Electric Wheel-Chair to economize it with Respect to Bangladesh, International Journal of Multidisciplinary Sciences and Eng. 2014.

11. Shanu Sharma, User Centric Designed Mechanism For stairs-climbing Wheelchair, $15^{\text {th }}$ National Conference on Machines and Mechanisms NaCoMM, 2011.

12. Sheng Lin Jzau, Wireless brain computer interface for electric wheelchairs with EEG and eye-blinking signals, International Journal of Innovative Computing, Information and Control, 2012.

13. Wellman, P., Design of a Wheelchair with Legs for People with Motor Disabilities, IEEE Transactions on Rehabilitative Eng., Vol. 3, pp.343-353, 1995.

14. MSC Inc., MSC Adams 2013 reference manual.

15. http://t2rerc.buffalo.edu/pubs/forums/mobility/forum/white_papers/motors.htm

16. http://www.daaam.info/Downloads/Pdfs/proceedings/proceedings_2011/0477_Geonea.pdf 